\title{
NEW GRADUATE NURSES' EXPERIENCES OF INTERACTIONS IN THE CRITICAL CARE UNIT
}

Farida Saghafi RN, NE, CNS, BSc, MNEd, PhD Candidate, School of Nursing, Australian Catholic University, Sydney, NSW, Australia

Jennifer Hardy RN, RM, BSc, MHPEd, PhD, Senior Lecturer and Clinical Practice Co-ordinator, Faculty of Nursing and Midwifery, Sydney Nursing School, University of Sydney, NSW 2006, Australia; jennifer.hardy@sydney.edu.au

Sharon Hillege RN, RM, BHS (Nursing), PhD, Senior Lecturer, School of Nursing \& Midwifery, College of Health \& Science, University of Western Sydney, NSW, Australia; s.hillege@uws.edu.au

\section{Correspondence:}

Farida Saghafi, ICU Nurse Educator/ Clinical Nurse Specialist, St Vincent and Mater Health, 25 Rocklands Rd, Crows Nest, NSW, 2065, Australia

Telephone: +610412435299

Email: fsaghafi@matersydney.com.au 


\section{ABSTRACT}

This paper reports on one of the key findings from a recent descriptive phenomenological study on lived experience of ten new graduate nurses (NGNs) in an Intensive Care Unit (ICU) in a major acute care hospital. Interpersonal relationships experienced by NGNs in ICU give rise to diverse thoughts, perceptions and feelings that may have significant impact on their professional development, job satisfaction and retention. The researcher conducted in-depth, semi structured audio-taped interviews to collect the data. Interaction with others as key theme and related subthemes: Interaction with patients, Interaction with other members of the ICU team, who is approachable, and feedback emerged. The NGNs' perception of their ability to interact with others, as part of their professional development, is influenced by both (i) how they see themselves and (ii) how they perceive that others see them.

Keywords: Nursing; Intensive Care Unit, graduate nurse, interaction, interprofessional relationship, transition program, confidence

\section{Introduction}

As new graduate nurses (NGNs) enter the workplace, they are faced with many demands and challenges (Butler \& Hardin-Pierce, 2005). Literature on the issue indicates that new graduate nurses are expected to reach prescribed milestones within a very short timeframe. Other challenges which arise are: persistent 


\section{New graduate nurse and others}

criticism about being ill prepared for the real world of clinical nursing practice; reality shock; and unsupportive work environments that do not foster trust (Halfer, 2007; Kramer, 1974; Parker, Plank \& Hegney, 2003). These factors impede nurses in accomplishing their work and increase pressure on retention (Laschinger, Finegan, Shamian, \& Wilk, 2001). Some of the milestones that need to be achieved, especially in the first six months of the new graduate program are; establishing oneself as a healthcare team member; acclimatising to the new job and organization, developing confidence and competence in clinical skills, and making sense of the role as a nurse relative to other healthcare professionals ( Duchscher, 2008; Halfer, 2007). Novice registered nurses in their transition to the professional role in Intensive Care Unit (ICU) have a variety of experiences with patients, families, and health care professionals especially nurse co-workers and doctors. These experiences give rise to diverse thoughts, perceptions and feelings that may negatively impact on NGN's professional development, job satisfaction, and retention.

Despite extensive research on the work experience of NGNs, few studies have addressed the perception of NGNs of interaction with other health professionals and patients in ICU.

In a larger study $[\mathrm{PhD}]$, the day-to-day experiences of NGNs in an ICU are explored. The researcher aims to discover what the experience is like for NGNs 
when they commence in the ICU as well as to explore the changes that occur in their attitudes and experience after 2-3 years of clinical practice in critical care setting. The focus for this paper is to highlight the importance of interaction in the intensive care setting from the new graduate nurses' perspective. For the purpose of this study, interaction represents relationship between NGNs and senior nurses, doctors, patients and their families and the effect it has on the NGNs. The study uses descriptive qualitative methodology.

\section{Background}

Most NGNs in New South Wales (NSW), Australia, on completion of a Bachelor of Nursing degree, progress through a New Graduate Program in their first year of practice. They are able to choose different clinical specialities in the employing hospital. Some specialities include ICU, orthopaedics, plastic surgery, urology, neurology, neurosurgery, gynaecology, and vascular surgery. An example of a program could be two rotations of three months each in a chosen speciality and or a six-month rotation in ICU. In 2009, NGNs could enter ICU as their first clinical placement.

The delivery of care in ICU demands a team effort and without the support and collaboration of the full ICU team little can be achieved (Vincent, 2006). Casey, Fink, Krugman, \& Propst (2004) identified that the NGN may feel unaccepted by their peers and experience difficulty communicating especially with doctors, as a 
new member of the team, in an acute care setting. McKenna and Newton (2007) conducted a research which involved 21 NGNs from four hospitals in Victoria, Australia. In this study it was recognised that after completing the new graduate program, NGNs felt a sense of belonging to a particular clinical setting.

There is considerable discussion in the literature about the nurse-physician relationship, nurse-patient relationship, nurse-nurse relationship, and communication skills in ICU (Belcher \& Jones, 2009; Dyess \& Sherman, 2009; Kelly \& Ahern, 2008; Manojlovich, 2009; Schmalenberg \& Kramer, 2009; Ulrich et al., 2006). Conversely, there is little information available that provides insight into the NGNs' experience and perception relating to the interactions with other members of critical care team and critically ill patients and their families.

Effective communication is vital to successful of care in ICU (Gauntlett \& Laws, 2008). Skilled communication is one of the standards for establishing and sustaining healthy work environments. Nurses must be as proficient in communication skills as they are with clinical skills (The American Association of Critical-Care Nurses, 2005). As new members of the team in ICU, NGNs, need to develop into their professional role, have a variety of experiences of interaction with others. These experiences give rise to diverse thoughts and emotional responses that may have a significant impact on the nurses' own professional development and socialization into this role. Other concerns of 
introducing new graduates into high acuity areas include capacities related to cognition, clinical judgement and decision making (Duchscher, 2008). However, the focus for this paper is on new graduates' experience of interacting with medical and nursing staff, patients and their families.

\section{Methodology}

A phenomenological approach has been adopted for this study as it aims to explore, analyse and describe particular phenomena. According to Husserl, the experience perceived by human consciousness has value and should be an object of scientific study. Human beings generally go about the business of daily living without critical reflection on their experiences, however, Husserl believed that a scientific approach was needed to bring out the essential components of the lived experiences specific to a group of people (Lopez \& Willis, 2004). It is assumed that there are unique everyday experiences of the phenomenon of being a NGN in ICU, that can be abstracted from the data and that this structure is independent of context. In addition, as the researcher was a nurse, applying "bracketing" ensured that the description of the participants' experience would be free of personal experiences and biases.

The interview questions were constructed to encourage in-depth reflection on the experiences of being a new graduate in ICU by participants. Bracketing prior knowledge helped to ensure purity of the analysis. The researcher also returned to 
each participant and asked if the exhaustive description was a true reflection of the participant's experiences. Requesting negative descriptions of the phenomenon under the investigation such as "Can you describe a situation in which you would feel that you were underestimated by other staff?" was helpful in comparing and contrasting the data (Speziale \& Carpenter, 2007).

\section{Data Collection}

The research was conducted in an ICU in a major acute care hospital in Sydney, NSW, with NGNs undertaking their new graduate program. After Ethical approval was granted by hospital and university's Human Research Ethics Committee, an informal meeting with all NGNs in the hospital assisted the researcher to develop questions for the interviews. In addition, this information session, oriented the new graduates to the research project. An advertisement flyer was displayed in the unit inviting potential participants. The researcher approached the NGNs who contacted her regarding the flyer. After informing the participants about the study verbally, via the information sheet and in person, consent was obtained prior to the interview. A clear explanation was given to participants indicating that they had the right to withdraw from the study, and that participation was voluntary. Confidentiality and anonymity of the data were assured. All transcript data were de-identified and the names of participants were kept separately to the interview transcripts and tapes. Whilst the researcher was familiar to the study population, the participants were not in a dependant or unequal relationship with 
researcher as the interviews were only conducted when the NGN no longer worked in the ICU.

Ten NGNs participated in the study. The participants were registered nurses who had graduated in the past 12 months. The participants were invited to provide demographic data, including: age, gender, past experience, and qualifications. Individual in-depth, semi structured audio-taped interviews were conducted away from the immediate workplace and in privacy. The interviews began with the researcher asking participants what it meant to them to be a NGN. Thereafter, a flexible interview guide was followed which included exploration of the NGNs' perceptions of communication with other health professions, other nurses, patients and their families. Each interview lasted from 1.5 to 2 hours (Minichiello, Aroni, Timewell, \& Alexander, 2008).

\section{Data analysis}

The audio-taped interviews were transcribed into a Microsoft word program. Each transcript was read and reread until themes were uncovered. This was done in order to understand the meanings of the experience of being a new graduate. Computer Assisted Qualitative Data Analysis System (CAQDAS) was used to: (i) automate and accelerate the coding process, (ii) provide a more complex way of looking at the relationships in the data, and (iii) provide a formal structure to develop the analysis (Hahn, 2008). The researcher used Colaizzi's seven- step 
procedure (1978) - a methodology which "involves analysing and observing behaviour within its own environment to examine experiences" (Burns \& Grove, 2009, p. 530). Significant statements relevant to the experiences of NGNs were extracted. These significant statements then were developed to formulate meanings. Themes were organised into clusters and were then integrated into an exhaustive description. The essential structure of the phenomenon was formulated. Finally, for further validation of the data, the participants were asked to evaluate the findings and to indicate if they truly represented their experience.

\section{Findings}

The participants (table 1) represented mostly a similar range of ages and had similar length of experience in ICU. NGNs in this research revealed that they held different views about interactions with other members of the ICU team some found these interactions to be challenging whilst others found them to be supportive. One key theme that emerged from the data was Interaction with others. Related subthemes were Interaction with patients, Interaction with other members of the ICU team, who is approachable, and feedback.

\section{[Insert Table 1 here]}

\section{Interaction with patients}

Interaction with patients refers to the communication between the NGN and patients in ICU. This level of communication had varying influences on the NGN. Some of NGNs expressed how they tried to hide their level of inexperience in 
ICU from their patients and their families. They felt this lack of experience would influence the level of trust the patient might have in their ability to carry out their care. Two examples are as follows:

..They would probably think "Oh... my god! You're not very experienced" or they might lose a bit of faith in you. And I probably would too if someone was looking after me and they said actually this is my first year out I would be like okay... it would be like what are they doing now .... No, I don't usually let on and if some just say directly how long have you been nursing .... Oh well I just avoid it. So no, I don't let them know. [Caroline]

...I was looking after a patient who had had major heart surgery and here I am looking after this person and the family says " have you been working here for long?" ... how do I get around saying oh yes I have only worked here for a month?... I just get around it and say I have been working here for a while instead of saying I am just learning everything and just get around it in a way to change the conversation and stuff. Because you don't want the family to think you have only had a month worth of experience, I change it by saying everyone here is very experienced and everyone has done other qualifications after their nursing degree. [Linda]

Some NGNs in this study used different ways to hide the fact they had limited experience in ICU. They avoided answering the question related to experience and even tried to camouflage their appearance, which labelled them as junior staff. Sophie expressed:

I would never ever wear the light colored shirt because if I wore the light colored shirt they would always ask me how long I had been out of uni. ... But if I wore the dark colour, they would always think that I had been out for a certain amount of time. For some reason they had in their head the dark uniform means that you are more senior and 
patients would trust things that you say and families would trust things that you said... it would just make things easier. It's really bad... it's pitiful.

\section{Interaction with other members of ICU team}

Interactions with other members of ICU team, within the context of this paper refers to new graduate nurses' communication with doctors and nursing staff in ICU and its effect on NGNs. Participants in this study agreed that interprofessional relationships among nursing and medical staff in ICU are more equitable than they had experienced on a general ward. For instance, Kylie noted:

At first coming from the ward, it is really different.... the doctor situation... it is a lot easier to talk to the doctors in Intensive Care, because you work in a tight [relationship].....you have to be communicating well with the doctors in Intensive Care where as on the wards it wasn't really like that... nobody spoke to the doctors.

Most of participants revealed that in interacting with doctors they found support and identified it as a good experience, 'I think their(doctors') communication with us is quite good' Lily claimed. Participants identified that as soon as the doctors knew they were NGNs they would patiently explain different clinical matters to them. The following quotations illustrate the NGNs' experience of communication with doctors as being supportive and understanding:

... Doctors were actually quite good I thought. Generally, I think most of them, if they knew you were new and.... you were introduced as soon as you came onto the unit as being a New Grad and someone new... so I found that that was quite good because they knew that you were new... they had no issue with explaining things. [Sophie] 
... Most of them (doctors) if they know you are a New Grad; they tend to explain things a bit more. [Mary]

However, three participants claimed different personalities among doctors would affect how approachable they were, especially at the beginning of their rotation. At times NGNs found interaction with doctors challenging and intimidating. For instance, Linda claimed:

I think first out ...yes I was very intimidated by the doctors, I didn't know how to approach them and sort of things like that, whereas if you are a more senior level you know how to communicate to the doctors and you can get things done a lot faster.

One of the factors that NGNs believed affected their relationship with the nursing staff and acceptance as a member of the team was their transiency in the unit. New graduate registered nurse transition programme in NSW (Australia) is a 12 month contract. On occasions the new graduates believed that because of the temporary nature of this employment, permanent staff did not consider them as a member of team. The participants identified having other new graduates as their peers, available to talk to and to share clinical experiences was a relief. Mary comments on lack of acceptance:

I think sometimes when you are a New Grad, not specifically in ICU but other places as well, they don't expect you to be there that long and sometimes they don't get to know you and things like that.

NGNs in the study reported that the nursing staff were not aware of their level of knowledge and skills hence, on occasions they would explain fundamental 
clinical nursing skills. Therefore, graduates stated they felt the need to continuously prove themselves as competent nurses to be part of the team and be accepted by their colleagues, as Sophie and Lucy explain:

...it can be difficult sometimes interacting with staff because they don't really know you and they don't know how much you know. [Sophie]

I think it is only to prove myself and I think there will be a time when I will have proved myself, not to be the perfect nurse but to be a competent nurse ...not that I am incompetent but I am not quite at that stage yet. [Lucy]

In addition, one of the NGNs expressed how she found that some senior nurses' interactions with NGNs were different compared to other staff:

....one of them, a CNS when I see how he interacts with other nurses that are above me I think there is hope for me, he is just testing me and making me do stuff and maybe in 6 months, 9 months everything will be fine . [Lucy]

\section{Who is approachable?}

The NGNs quickly identified the most approachable staff members for support and guidance. In the majority of cases, this person proved to be the closet to them in the nursing hierarchy. Lucy and Linda commented:

It is good in a way because it makes it quite clear, as whom the best people are to ask for advice ... on different levels. For example if I needed advice on a technical nursing matter, I would go to someone who was maybe a CNS or close to being a CNS. Whereas if I needed some more personal advice like: I am finding this really hard, and I didn't feel comfortable; discussing that with someone that was sort of close to the top of that chain of hierarchy. I might go to someone that was maybe a couple of years in.... that 
maybe hadn't done their Post Grad yet, who maybe would be able to empathise more where I was coming from, and be able to feel more comfortable communicating that information with them.

You sort of find out who you can ask and who you can't, and those more willing to help you and you keep going back to those people and asking.

\section{Feedback}

When asked to share their experience of communication as NGNs in ICU, the participants reported how the positive feedback from their colleagues or patients boosted their confidence. Caroline described her experience as "It just took the pressure off and I thought well maybe I am not that useless". Another participant shared feeling of satisfaction achieved by the positive feedback that confirmed her role in patient's recovery:

I have had a couple of patients that have said ... "you are a really good nurse keep going this way, don't change, make sure you stay in nursing so that other people have the same experience that I have"; and you come out and you feel really good; and you think like wow.... I really made a difference to someone, and maybe I did make the right decision by being a nurse. [Rose]

Formal appraisal was important to NGNs whilst they were going through their placement in ICU. The participants believed feedback from the nursing manager was as an opportunity to evaluate their progress and achievement during the new graduate program: 
I think, they [senior nurses] need to say "yes you have had a bad day but you did well we will see you tomorrow" just a bit of positive feedback would do wonders... Like I think, I had a chat with one of the other New Grads and that was probably one of the most important things that we said we were never told that we were doing well. You can't judge how well you are doing unless you get feedback; unless you are getting negative criticism all the time, which you seem like you are when you are a New Grad, there is no obvious sign that you are doing really bad. [Rose]

Feedback was also seen as playing a role in NGNs' reflection on their performance and development during their time in ICU. One NGN expressed:

I do strive on feedback, I find that really important just so I can take it on and improve my skills. Sometimes I will ask people and go "am I doing the right thing" and different stuff, because I like to get feedback off people about doing stuff. [Linda]

\section{Discussion}

In this paper the experiences of a number of NGNs' interaction with other health care professionals in a critical care setting (ICU) has been described. Effective communication is integral to the success of any work environment; it is vitally important that NGNs have positive and effective communication experiences, and recognition of their expectations.

Perhaps of a great significance is the new graduates' interaction with patients and their need to "hide level of expertise" to prevent loss of the patient's trust. There is sufficient support in the literature to identify that trust is a crucial element in establishing an effective nurse-patient interaction (College of Nurses of Ontario, 2009; Fleischer, Berg, Zimmermann, Wüste, \& Behrens, 2009; Lotzkar \& 


\section{New graduate nurse and others}

Bottorff, 2001; Mok \& Chiu, 2004; Sellman, 2007). The importance of trust and feeling safe in nurse-patient interactions was highlighted, as NGNs in this study tried to gain the trust by hiding their perceived lack of expertise so that the patient felt safe under their care. Endeavour to disguise feeling of inadequacy as a normal behaviour by new graduates has been reported by Druchscher (2008). The importance of previous nursing experience in developing trust between the new graduate nurse and patient has been described by Belcher and Jones' study (2009) in a qualitative research study involving NGNs in a Melbourne Metropolitan hospital, in Australia. They explored the NGNs' experience of developing trust in the nurse-patient relationships and found that developing rapport was the first step to building a trusting relationship with the patient. In order to develop rapport, new graduates identified the previous nursing experience as a major theme. There is a paucity of research regarding NGNs' perceptions about developing a trusting nurse-patient relationship, however, this study illustrated that these NGNs understood the importance of trust and they believed it could influence patient's acceptance of care (Belcher \& Jones, 2009).

During the interviews over half the participants frequently used the term "supportive" to describe the nursing and medical staff in ICU. The term support to them was described as, support in their clinical practice as well as guidance in patient management. Conversely, NGNs reported experiences of poor communication with some doctors and nurses in ICU. Kelly and Ahern (2008) in 


\section{$\underline{\text { New graduate nurse and others }}$}

a phenomenological study in Australia noted the different personalities and attitudes among doctors and senior nurses overwhelmed NGNs, and in general, they found communication with doctors relatively uncomfortable. The lack of respect from the experienced nurses toward new graduate nurses; has often been cited in the literature as a major challenge (Casey et al 2004; Dyess \& Sherman, 2009; Kelly \& Ahern, 2008; McKenna et al 2003). Rosenstein and O’Daniel (2008) concur with these finding and revealed that if the participants experienced difficulties or challenges in communication with a member of the ICU team they elected to avoid approaching that person voluntarily in the future.

The new graduate, can be described as a novice, and therefore, needs guidance in applying knowledge to clinical experiences (Benner, 1984). Senior nurses could reinforce this guidance by providing feedback to NGNs. The findings of this study indicate that the NGNs prefer to receive frequent and regular feedback and formal appraisal from senior nursing staff. This resonates with Duchscher (2009) new graduate nurses' transition conceptual framework. In Sociocultural and developmental aspect of transition shock experiences, Duchsecher identified the need for affirming and critical feedback from senior colleagues and also absence of formal feedback for novice practitioners. Casey et al (2004) also found there was a relatively high level of satisfaction with positive feedback from managers and co-workers among NGNs. 


\section{New graduate nurse and others}

The NGNs in this study reported a lack of regular feedback, especially formal feedback, from their senior colleagues and mangers. The participants emphasized that they valued constructive feedback. They perceived feedback as an indicator to measure their clinical practice progression.

\section{Conclusion and recommendations:}

The NGNs who participated in this study provided valuable descriptions of both their positive and negative experiences with nursing and medical colleagues, as well as patients during their transition to practice phase. The results of this study provide considerable insight into NGN's perceptions of interactions with patients and other health professionals in ICU. Many reported that they attempted to hide their inexperience from the patients and the fact that they have been out of university for less than a year and had only a few months of experience in ICU. The participants were able to describe their experiences in this new role in terms that reflected interaction with other members of ICU team that was both supportive as well as challenging. They described characteristics such as "not approachable" among some senior colleagues. They reported that they expected to receive regular feedback while acquiring the knowledge and skills necessary to be trustworthy and accepted by other members of ICU team.

There were some variations in the responses from these NGNs that could be linked to individual personalities. The more outspoken the participant was, the more positive their experience. These experiences so richly described by the 
NGNs in this study indicate that while giving positive feedback rarely occurred, this feedback could have provided support and guidance; including the confidence necessary to practice nursing successfully and perhaps may have impacted on the retention of NGNs in ICU.

Further studies in cross clinical settings would be helpful to determine the prevalence of these experiences for NGNs in other areas of clinical practice.

\section{Acknowledgements}

We thank the new graduates, who shared their stories with us, the senior educator of the hospital who organized the initial meeting with new graduate.

\section{References:}

Belcher, M., \& Jones, L. (2009). Graduate nurses' experiences of developing trust in the nurse-patient relationship. Clinical Nursing, 31(2), 142-152.

Benner, P. (1984). From novice to expect: Excellence and power in clinical nursing practice. Menlo Park, CA: Addison-Wesley.

Burns, N., \& Grove, S. K. (2009). The Practice of Nursing Research: Appraisal, Synthesis, and Generation of Evidence. St Louise, Missouri: Saunders Elsevier.

Butler, K., \& Hardin-Pierce, M. (2005). Leadership Strategies to Enhance the Transition From Nursing Student Role to Professional Nurse. Nursing Leadership Forum, 9(3), 110-117.

Casey, K., Fink, R., Krugman, M., \& Propst, J. (2004). The Graduate Nurse Experience. Journal of Nursing Administration, 34(6), 303-311.

Colaizzi, P. (1978). Psychological research as the phenomenologist views it. In $R$. Valle \& M. King (Eds.), Existential phenomenological alternatives for psychology. New York: Oxford University Press.

College of Nurses of Ontario. (2009, 2006). Practice standard: therapeutic nurseclient relationship. Retrieved 23/07, 2010, from http://www.cno.org/docs/prac/41033_Therapeutic.pdf 
Duchscher, J. B. (2008). A Process of Becoming: The Stages of New Nursing Graduate Professional Role Transition. The Journal of Continuing Education in Nursing, 39(10), 441-450.

Duchscher, J. (2009). Transition Shock: the initial stage of role adaptation for newly graduated Registered Nurses. Journal of Advance Nursing, 65(5), 1103-1113.

Dyess, S., \& Sherman, R. (2009). The First Year of Practice: New Graduate Nurses' Transition and learning Needs. The Journal of Continuing Education in Nursing, 40(9), 403-410.

Fleischer, S., Berg, A., Zimmermann, M., Wüste, K., \& Behrens, J. (2009). Nursepatient interaction and communication: a systematic literature review. Journal of Public Health, 17, 339-353.

Gauntlett, R., \& Laws, D. (2008). Communication skills in critical care. Continuing Education in Anaesthesia, Critical Care \& Pain, 8(4), 121124.

Hahn, C. (2008). Doing Qualitative Research Using Your Computer. London: Sage.

Halfer, D. (2007). A Magnetic Strategy for New Graduate Nurses. Nursing Economics, 25(1), 6- 12.

Kelly, J., \& Ahern, K. (2008). Preparing nurses for practice: A phenomenological study of the new graduate in Australia. Journal of Clinical Nursing, 18, 910-918.

Kramer, M. (1974). Reality Shock: Why nurses leave nursing. St. Louise: MO: Mosby.

Laschinger, H. K. S., Finegan, J., Shamian, J., \& Wilk, P. (2001). Impact of structural and psychological empowerment on job strain in nursing work settings: Expanding Kanter's Model. Journal of Nursing Administration, 31(5), 260-272.

Lopez, K., \& Willis, D. (2004). Descriptive Versus Interpretive Phenomenology: Their Contributions to Nursing Knowledge. Qualitative Health Research, 14(5), 726-735.

Lotzkar, M., \& Bottorff, J. (2001). An observational study of the development of a nurse-patient relationship. Clinical Nursing Research 10(3), 275-294.

Manojlovich, M. (2009). Intensive Care Units, Communication Between Nurses and Physicians, and Patient's Outcomes. American Journal of Critical Care, 18(1), 21 - 30.

McKenna, B. G., Smith, N. A., Poole, S. J., \& Coverdale, J. H. (2003). Horizontal violence: experience of Registered Nurses in their first year of practice. Journal of Advance Nursing, 42(1), 90-96.

Minichiello, V., Aroni, R., Timewell, E., \& Alexander, L. (2008). In-depth interviewing: Researching people. Melbourne: Longman Cheshire. 
Mok, E., \& Chiu, P. (2004). Nurse-patient relationships in palliative care. Issues and Innovations in Nursing Practice Journal of Advanced Nursing, 48(5), 475-483.

Parker, V., Plank, A., \& Hegney, D. (2003). Adequacy of support fot new graduates during their transition into the workplace: A Queensland, Australia study. International Journal of Nursing Practice, 9, 300-305.

Rosenstein, A. H., \& O'Daniel, M. (2008). A Survey of the Impact of Disruptive Behaviors and Communication Defects on Patient Safety. The Joint Commission Journal on Quality and Patient Safety, 34(8), 464-471.

Schmalenberg, C., \& Kramer, M. (2009). Nurse-Physician Relationships in Hospitals: 20000 Nurses Tell Their Story. Critical Care Nurse, 29(1), 7483.

Sellman, D. (2007). Trusting patients, trusting nurses. Nursing Philosophy, 8, 2836.

Speziale, H. S., \& Carpenter, D. R. (2007). Qualitative Research in Nursing: Advancing the Humanistic Imperative (4th ed. ed.). Philadelphia, PA: Lippincott Williams \& Wilkins.

The American Association of Critical-Care Nurses. (2005). AACN Standards for Establishing and Sustaining Healthy Work Environments: A Journey to Excellence. American Journal of Critical Care, 14, 187-197.

Ulrich, B. T., Lavandero, R., Hart, K. A., Woods, D., Leggett, J., \& Taylor, D. (2006). Critical Care Nurses' Work Environments: A Baseline Status Report. Critical Care Nurse, 26(5), 46- 57.

Vincent, J.-L. (2006). Teamwork and the Future of Intensive Care Medicine. Paper presented at the The 26th International Symposium of Intensive Care and Emergency Medicine Brussels.

Table 1- Characteristics of new graduate nurses in the study

\begin{tabular}{|l|l|l|l|}
\hline $\begin{array}{c}\text { Participants } \\
\text { (Pseudonym) }\end{array}$ & Age & $\begin{array}{l}\text { Experience } \\
\text { in ICU }\end{array}$ & Past work history \\
\hline Adam & $20-30$ & 5 months & Nil \\
\hline Caroline & $41-50$ & 6 months & Nil \\
\hline Kate & $20-30$ & 3 months & Nil \\
\hline Kylie & $20-30$ & 6 months & AIN \\
\hline Lily & $20-30$ & 6 months & EN \\
\hline Linda & $20-30$ & 6 months & AIN \\
\hline Lucy & $20-30$ & 3.5 months & AIN \\
\hline Mary & $20-30$ & 4 months & Nil \\
\hline Rose & $20-30$ & 6 months & Nil \\
\hline Sophie & $30-40$ & 6 months & Nil \\
\hline
\end{tabular}

